\title{
Modelling and Analysis of Composite as an Alternative Material for Leaf Spring
}

\author{
Smita C. Saddu ${ }^{1}$, Vikas V. Shinde ${ }^{2}$ \\ ${ }^{\prime}$ (Mechanical Department, Pune University, India) \\ ${ }^{2}$ (Mechanical Department, Pune University, India)
}

\begin{abstract}
Weight reduction is now day's main issue in the automobile industry. Reducing weight while increasing or maintaining strength of product is getting to be highly important. The automobile industry has shown increasing interest in the replacement of steel spring with composite leaf spring due to high strength to weight ratio. Modern composites using unidirectional fiber-reinforced matrices of various types have created a revolution in high-performance structures in recent years. A current leaf spring is made up of a steel material which is having high weight, low natural frequency, high corrosion, more noise and the property of material is changing when the load is acting. Therefore current multiple leaf spring needs to be replaced by composite material leaf spring. Advanced composite materials offer significant advantages in strength, stiffness, high natural frequency and light weight relative to conventional metallic materials. This paper describes the analysis of steel and composite material leaf spring. Then these results are compared with that of the experimental results.
\end{abstract}

Keywords: Leaf spring, Steel, Composite material, Constant cross-section design, FEA, Modelling, Testing.

\section{Introduction}

Weight reduction has been the main focus of automobile manufacturers in the present scenario. Weight reduction can be achieved primarily by the introduction of better material, design optimization and better manufacturing processes. The suspension leaf spring is one of the potential items in automobiles as it accounts for nearly $10 \%-20 \%$ of the unsprung weight. Reducing weight of the unspurng mass will achieves the vehicle with more fuel efficiency and improved riding qualities. The introduction of composite materials was made it possible to reduce the weight of leaf spring without any reduction on load carrying capacity and stiffness.

\section{Leaf Spring}

Leaf spring is one of the oldest suspension systems .Leaf spring (also known as flat plate) are made up of plat plate. Leaf spring can be designed in two ways mono leaf spring or multi leaf spring. Mono leaf spring is used for the lighter vehicle which consists of a single steel plate. While in the multi leaf spring a leaf spring can be made from several leaves stacked on top of each other in several layers, often with progressively shorter leaves. Leaf springs can serve locating and to some extent damping as well as springing functions. While the inter leaf friction provides a damping action. A leaf spring can either be attached directly to the frame at both ends or attached directly at one end, usually the front, with the other end attached through a shackle, a short swinging arm. The shackle takes up the tendency of the leaf spring to elongate when compressed and thus makes for softer springiness.

Function of the leaf spring is of spreading the load more widely over the vehicle's chassis, whereas coil springs transfer it to a single point. Unlike coil springs, leaf springs also locate the rear axle, eliminating the need for trailing arms and a rod, thereby saving cost and weight in a simple live axle rear suspension. A further advantage of a leaf spring over a helical spring is that the end of the leaf spring may be guided along a definite path.

\section{Material for Leaf Spring}

The material used for leaf springs is usually a plain carbon steel having 0.90 to $1.0 \%$ carbon. The leaves are heat treated after the forming process. After the heat treatment process spring steel products gets greater strength and therefore greater load capacity, greater range of deflection and better fatigue properties.

\section{Literature Survey}

Mahmood M. Shokrieh et al. [1] worked on four-leaf steel spring used in the rear suspension system of light vehicles is analyzed using ANSYS V5.4 software. He used optimisation technique for reducing the weight. The objective was to obtain a spring with minimum weight that is capable of carrying given static external forces without failure. Pankaj Saini et al. [2] have compared the stresses and weight saving of composite leaf 
spring with that of steel leaf spring. The design constraint is stiffness. The material selected was glass fiber reinforced polymer (E-glass/epoxy), carbon epoxy and graphite epoxy is used against conventional steel. From the results he concluded that $\mathrm{E}$ glass/Epoxy is the best material for leaf spring by considering all the factors. M.Venkates And D.Helmen Devaraj [3] The objective of his paper is compare the load carrying capacity, stiffness and weight savings of composite leaf spring with that of steel leaf spring. A weight reduction of $76.4 \%$ is achieved by using optimized composite leaf spring. B.Vijaya Lakshmi et al. [4] has presented the static analysis on 8-leafs. From the results she concluded that E-glass epoxy is better than using Mild-steel as though stresses are little bit higher than mild steel.

\section{Specification Of Problem Statement And Objective}

The current leaf spring is of multiple leaf spring types with a steel material. It has high weight, low natural frequency, high corrosion, more noise. So there is a need of use of better material than the steel. Introduction of composite materials was made it possible to reduce the weight and cost of leaf spring without any reduction on load carrying capacity and stiffness. So the objective of the project is to compare the composite material leaf spring with that of steel leaf spring with parameter of stresses and stiffness.

\section{Composite Material}

Composite materials are ideal for structural application where high strength to weight and stiffness to weight ratio are required. These materials are basically hybrid materials formed of multiple materials in order to utilize their individual structural advantages in a single structural material. The composite material then has the properties of the two materials that have been combined. The advantage of composite materials is that, if well designed, they usually exhibit the best qualities of their components or constituents and often some qualities that neither constituent possesses. Some of the properties that can be improved by forming a composite material are

- Strength
- Stiffness
- Thermal insulation
- Therrar resistance
$\quad$ conductivity

- Fatigue life

- Corrosion resistance

- Weight

- Attractiveness

- Acoustical insulation

Naturally, not all of these properties are improved at the same time nor is there usually any requirement to do so. In fact, some of the properties are in conflict with one another, e.g., thermal insulation versus thermal conductivity. . Modern composites using fiber-reinforced matrices of various types have created a revolution in high-performance structures in recent years. Advanced composite materials offer significant advantages in strength and stiffness coupled with light weight, relative to conventional metallic materials.

\section{Fibres Selection}

The commonly used fibers are carbon, glass, keviar, etc. Among these, the glass fiber has been selected based on the cost factor and strength. The types of glass fibers are $\mathrm{C}$ glass, $\mathrm{S}$-glass and E-glass. The $\mathrm{C}$-glass fiber is designed to give improved surface finish.S-glass fiber is design to give very high modular, which is used particularly in aeronautic industries. The E-glass fiber is a high quality glass, which is used as standard reinforcement fiber for all the present systems well complying with mechanical property requirements. Thus, E-glass fiber was found appropriate for this application.

\section{Resins Selection}

In a FRP leaf spring, the inter laminar shear strengths is controlled by the matrix system used. Since these are reinforcement fibers in the thickness direction, fiber do not influence inter laminar shear strength. Therefore, the matrix system should have good inter laminar shear strength characteristics compatibility to the selected reinforcement fiber. Many thermo set resins such as polyester, vinyl ester, epoxy resin are being used for fiber reinforcement plastics (FRP) fabrication. Among these resin systems, epoxies show better inter laminar shear strength and good mechanical properties. Hence, epoxide is found to be the best resins that would suit this application different grade of epoxy resins.

Table 1: Mechanical Property of E-glass/Epoxy material

\begin{tabular}{|l|l|}
\hline \multicolumn{1}{|c|}{ Properties } & Value \\
\hline Tensile modulus along X direction (Ex), MPa & 43000 \\
\hline Tensile modulus along Y direction (Ey), MPa & 6500 \\
\hline Tensile modulus along Z direction (Ez), MPa & 6500 \\
\hline Poisson ratio along XY direction (PRxy) & 0.27 \\
\hline Poisson ratio along YZ direction (PRyz) & 0.6 \\
\hline Poisson ratio along ZX direction (PRzX) & 0.6 \\
\hline
\end{tabular}




\begin{tabular}{|l|l|}
\hline Shear modulus along XY direction(Gxy),MPa & 4500 \\
\hline Shear modulus along YZ direction(Gyz),MPa & 2500 \\
\hline Shear modulus along ZX direction(GzX),MPa & 2500 \\
\hline Mass density of the material $(\rho), \mathrm{Kg} / \mathrm{mm}^{3}$ & 0.000005 \\
\hline
\end{tabular}

\section{Specification of Existing Leaf Spring}

Table 2 shows the specification of a mono leaf spring of a Light commercial vehicle.

Table 2: Specification of Existing Leaf Spring

\begin{tabular}{|l|l|l|}
\hline Sr. No & Parameter & Value \\
\hline 1 & Total length of the spring & $1160 \mathrm{~mm}$ \\
\hline 2 & No. of full length leave (Master Leaf) & 01 \\
\hline 3 & Thickness of leaf spring & $15 \mathrm{~mm}$ \\
\hline 4 & Camber distance & $116 \mathrm{~mm}$ \\
\hline 5 & Width of leaf spring & $70 \mathrm{~mm}$ \\
\hline
\end{tabular}

\section{Solid Modelling of Leaf Spring in CATIA}

Leaf spring with dimension is first modelled in the CATIA V5R19 then it is imported in ANSYS Version 2012.

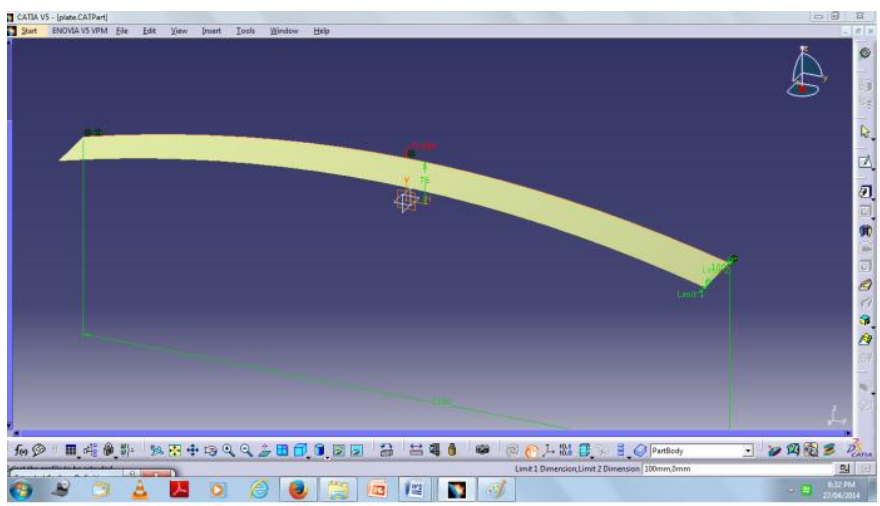

Fig.1: CATIA model of leaf spring

\section{Element Type}

\section{Analysis Using Ansys}

The geometry, node locations, and the coordinate system for this element are shown in below figure: "SHELL63 Geometry". The element is defined by four nodes, four thicknesses, elastic foundation stiffness, and the orthotropic material properties. Orthotropic material directions correspond to the element coordinate directions. The element $\mathrm{x}$-axis may be rotated by an angle THETA (in degrees). The thickness is assumed to vary smoothly over the area of the element, with the thickness input at the four nodes. If the element has a constant thickness, only TK (I) need be input. If the thickness is not constant, all four thicknesses must be input. The elastic foundation stiffness (EFS) is defined as the pressure required producing a unit normal deflection of the foundation. The elastic foundation capability is bypassed if EFS is less than, or equal to, zero.

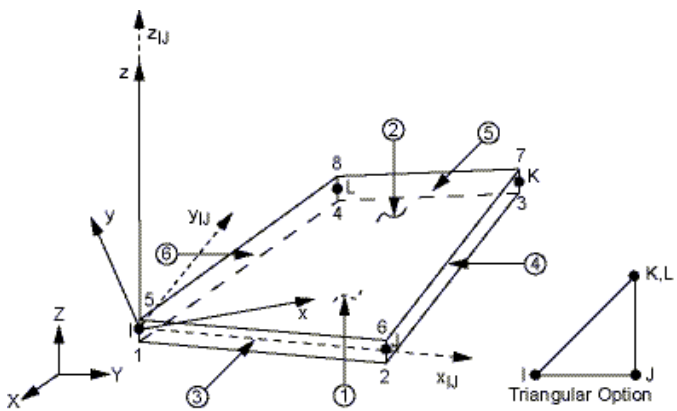

Fig.2: Shell63 Geometry

\section{Stress Analysis of Metallic Leaf Spring}

First step is to import the CATIA model in ANSYS. Symmetric boundary condition is used in $\mathrm{x}$ direction for reducing time required during meshing. Applying the different load on the master leaf e.g.: $50 \mathrm{~kg}$, 
$100 \mathrm{~kg}$, and $150 \mathrm{~kg}$ etc. For the load of $50 \mathrm{~kg}$ the maximum displacement in $\mathrm{Y}$ direction is $10.578 \mathrm{~mm}$. For the load of $100 \mathrm{~kg}$ maximum displacement in $\mathrm{Y}$ direction is $21.156 \mathrm{~mm}$. For the load of $150 \mathrm{~kg}$ the maximum displacement in Y direction is $31.734 \mathrm{~mm}$. At $150 \mathrm{Kg}$ load the von-misses stress or maximum equivalent stress of flat plate is $353.156 \mathrm{MPa}$

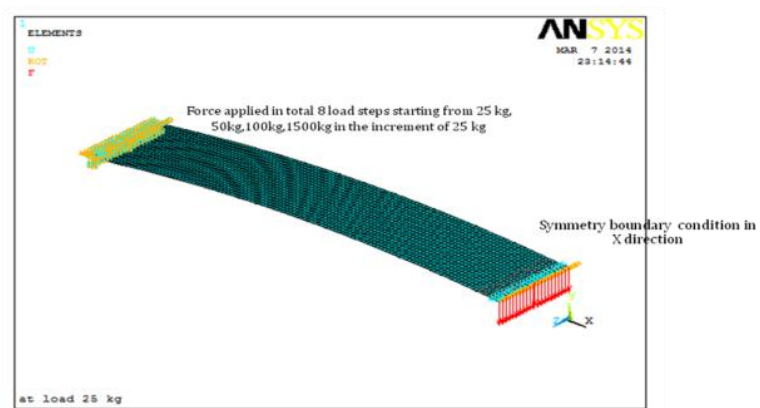

Fig.3: Boundray Condition

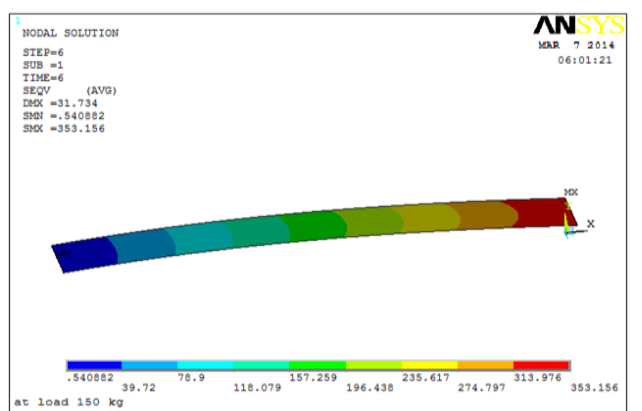

Fig.4:von-mises stress 353.156 MPa @ load of $150 \mathrm{~kg}$

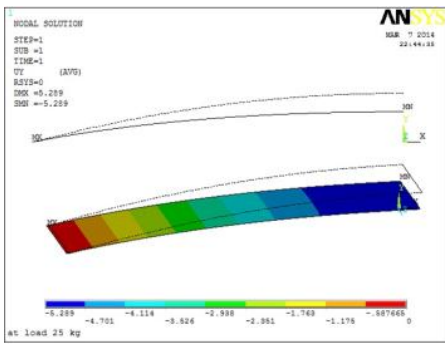

Fig.5: UY is $10.578 \mathrm{~mm} @$ load of 50 $\mathrm{Kg}$.

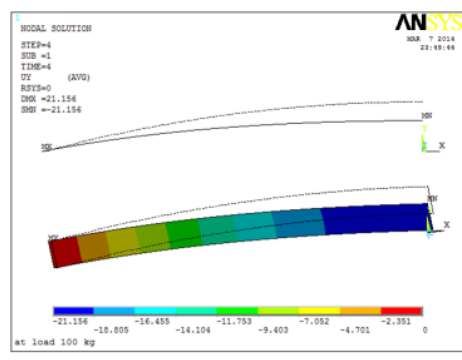

Fig.6: UY is $21.156 \mathrm{~mm} @$ load of $100 \mathrm{~kg}$

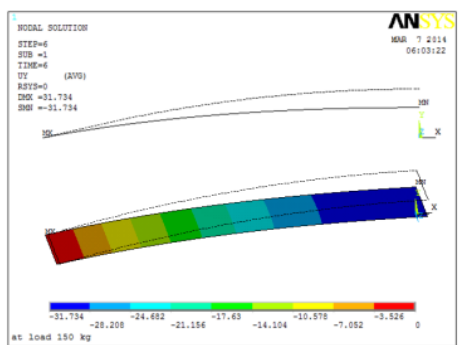

Fig.7: UY is $31.734 \mathrm{~mm}$ @ load of $15 \mathrm{~kg}$

\section{Stress Analysis of E-Glass/Epoxy Material Leaf Spring:}

Element used for composite material is SOLID95.SOLID 95 is a higher-order version of the 3-D 8node solid element. It is having three degree of freedom per node translation $\mathrm{x}, \mathrm{y}$ and $\mathrm{z}$ direction. For fiber element pipe 16 is used. Pipe 16 has six degree of freedom at two translations in the nodal $\mathrm{x}, \mathrm{y}$, and $\mathrm{z}$ axes. After modeling and meshing the composite next step is to apply different load on the plate. Applying the different load on the master leaf e.g.: $50 \mathrm{~kg}, 100 \mathrm{~kg}$, and $150 \mathrm{k}$ etc.

For the load of $50 \mathrm{~kg}$ the maximum displacement in $\mathrm{Y}$ direction is $9.27 \mathrm{~mm}$. For the load of $100 \mathrm{~kg}$ maximum displacement in $\mathrm{Y}$ direction is $16.53 \mathrm{~mm}$. For the load of $150 \mathrm{~kg}$ the maximum displacement in $\mathrm{Y}$ direction is $27.80 \mathrm{~mm}$. At $150 \mathrm{Kg}$ load the von-misses stress or maximum equivalent stress of flat plate is 139.9 $\mathrm{MPa}$.

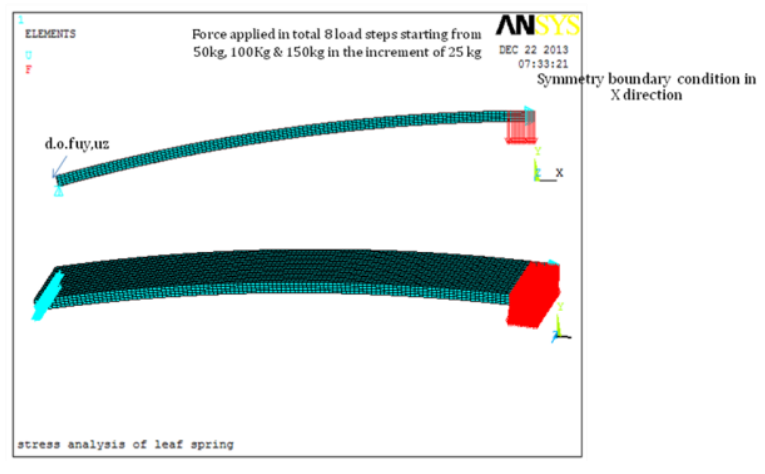

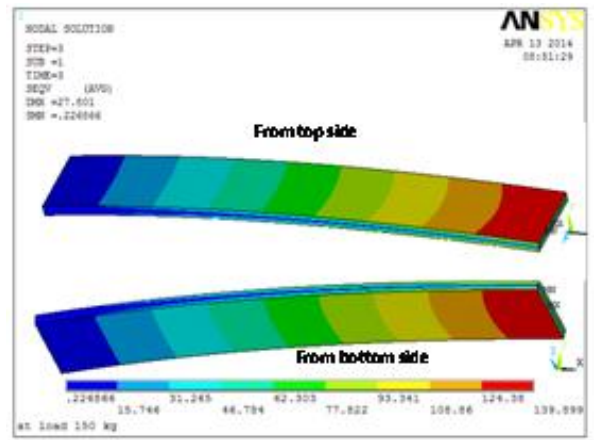

Fig.8: von-mises stress 139.9 MPa @ load of $150 \mathrm{Kg}$ 

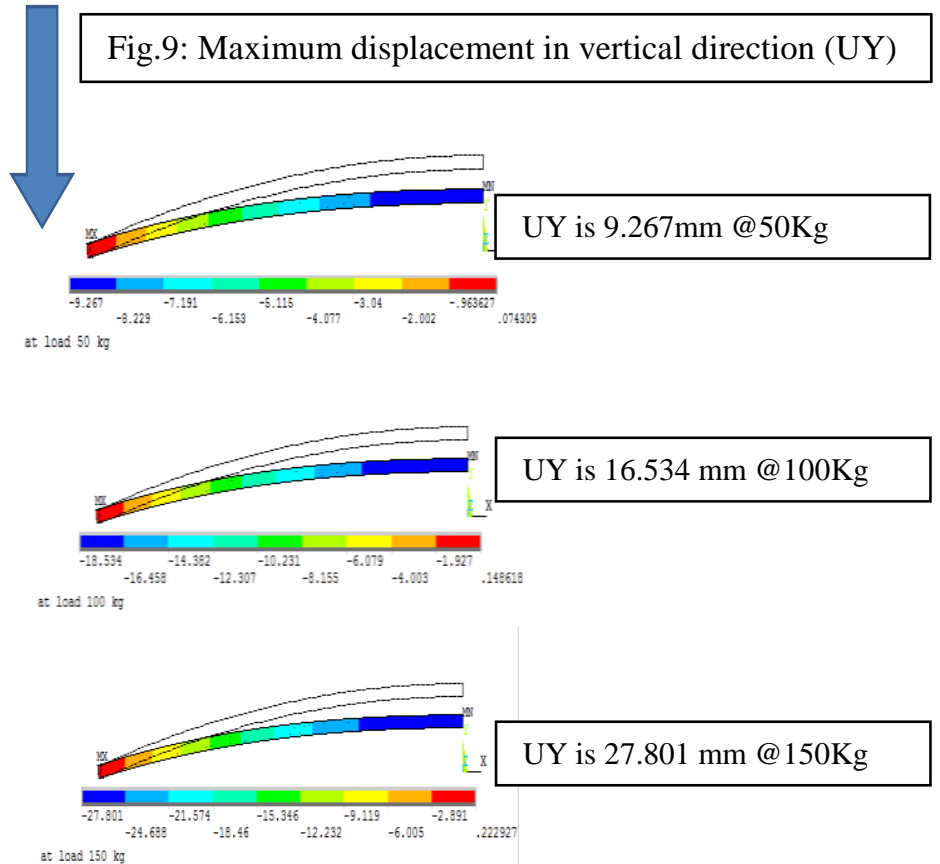

Table 3: Comparison of FEA results of loading on composite leaf \& steel leaf spring

\begin{tabular}{|c|c|c|c|c|}
\hline \multirow{2}{*}{$\begin{array}{c}\text { Load in } \\
\text { (kg) }\end{array}$} & \multicolumn{2}{|c|}{ Deflection in vertical direction (mm) } & \multicolumn{2}{c|}{ Max. eqv. Stress or von-mises stress (N/mm ${ }^{2)}$} \\
\cline { 2 - 5 } & $\begin{array}{c}\text { Composite material leaf } \\
\text { spring }\end{array}$ & $\begin{array}{c}\text { Steel material leaf } \\
\text { spring }\end{array}$ & $\begin{array}{c}\text { Composite material leaf } \\
\text { spring }\end{array}$ & Steel material leaf spring \\
\hline $\mathbf{5 0}$ & 9.2 & 10.5 & - & 117 \\
\hline $\mathbf{1 0 0}$ & 16.5 & 21.15 & - & 235 \\
\hline $\mathbf{1 5 0}$ & 27.8 & 31.7 & 139 & 353 \\
\hline
\end{tabular}

\section{Manufacturing Process}

Prototype which is having the constant cross section design was fabricated as per desired dimension by using Hand layup technique. In this process mould is made up from the plywood material. After manufacturing cavity of suitable size apply the wax/gel on the surface. The glass fibers were cut to desired length, so that they can be deposited on mould layer- by-layer during fabrication of composite leaf spring. Prepare the solution of resin \& Place the first layer of glass fibre chopped mat on mould followed by epoxy resin solution over mat. Wait for 5-10 min. Repeat the procedure till the desired thickness was obtained. The duration of the process may take nearly $30 \mathrm{~min}$. And finally remove the composite material leaf spring from mould.

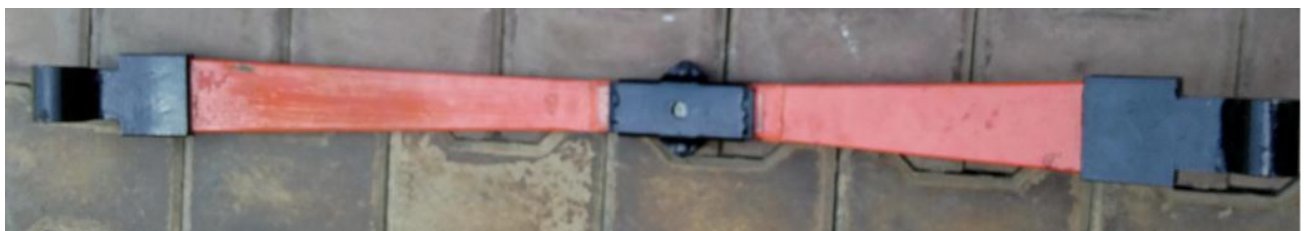

Fig.10: Leaf springs made from composite material

\section{Testing of Composite material Mono Leaf Spring}

The composite material leaf springs are tested by using Universal Testing Machine for static load condition. The experimental set up is shown in the fig. The spring is loaded from zero to some value for the reference we have taken some load for e.g.: $50 \mathrm{~kg}, 100 \mathrm{~kg}$, and $150 \mathrm{~kg}$. The load is applied at the centre of spring; the vertical deflection of the spring centre is recorded. 


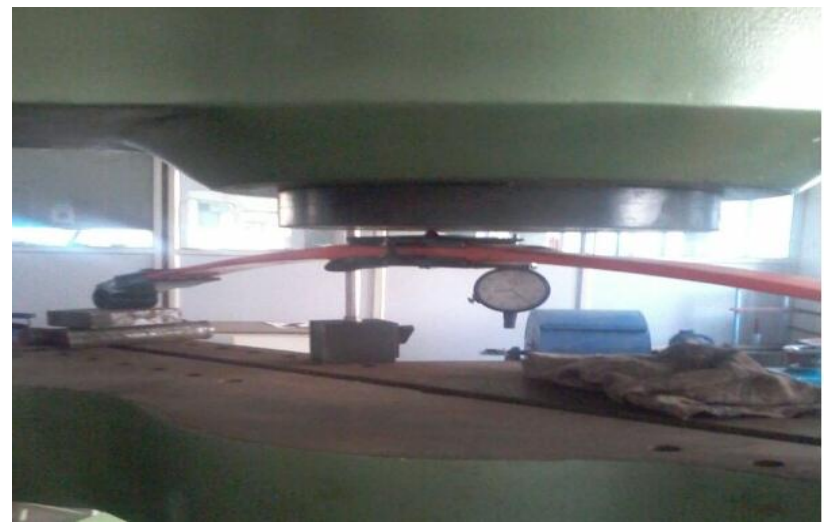

Fig.11: Static test of composite mono leaf spring

\section{Results And Discussions}

Experimental results from testing the composite material leaf springs under static loading containing the stresses and deflection are listed in the Table 4. These results are also compared with FEA in Table 3. Testing has been done for unidirectional E Glass/Epoxy mono composite leaf spring only. The steel leaf spring was replaced with an composite one. From the table it is concluded that the stresses in the composite leaf spring are much lower than that of the steel spring. So it proves that composite material is more effective than the conventional leaf spring.

Table 4: Experimental \& FEA results comparison for loading on composite leaf spring

\begin{tabular}{|c|c|c|}
\hline \multirow{2}{*}{$\begin{array}{c}\text { Load } \\
(\mathbf{k g}) .\end{array}$} & \multicolumn{2}{|c|}{ Deflection in Y direction mm } \\
\cline { 2 - 3 } & Experimental Results & FEA results \\
\hline $\mathbf{5 0}$ & 8.4 & 9.2 \\
\hline $\mathbf{1 0 0}$ & 15.2 & 16.5 \\
\hline $\mathbf{1 5 0}$ & 25.4 & 27.8 \\
\hline
\end{tabular}

\section{Conclusion}

This work involves the comparison of convention leaf spring with that of the composite material leaf spring under static loading conditions the model is preferred of CATIA V5R19. Then analysis is done through CATIA. From the result it is concluded that stresses developed in the composite material leaf spring is less as compared with that of the steel material leaf spring. So it proves that composite material is more effective and economical than the conventional leaf spring spring with similar design specification

\section{Future Work}

a) Analysis of leaf spring by varying thickness.

b) By changing fiber-orientation of composite material.

\section{Referances}

[1] Mahmud M. Shokrieh, Davood Rezaei,; Analysis and optimization of a composite leaf spring, Composite Structures 2003(60), pp. 317-325.

[2] Pankaj Saini, Ashish Goel, Dushyant Kumar;, Design and analysis of composite leaf spring for light vehicles, International Journal of Innovative Research in Science, Engineering and Technology, 2013(02),pp. 1-10.

[3] M.Venkatesan, D.Helmen Devaraj,; Design and analysis of composite leaf spring in light vehicle, International Joural of Modern Engineering Research (IJMER, 2012(02), pp. 213-218.

[4] B.Vijaya Lakshmi, Satyanarayana,; Static and dynamic analysis on composite leaf spring in heavy vehicle, International Journal of Advanced Engineering Research and Studies, 2012(2), pp80-84.

[5] Shao-yun fu, bernd lauke,; Effects of fiber length and fiber orientation distributions on the tensile strength of short-fiber-reinforced polymers, International Journal of Modern Engineering Research, Composites Science and Technology, 1996(56) pp. 1179-1190.

[6] Gulur Siddaramanna, Shiva Shankar, Sambagam Vijayarangan.; Mono Composite Leaf Spring for Light Weight Vehicle Design,End Joint Analysis and Testing, Materials Science, 2006(12), pp. 220-225. 